\title{
JUURNAL_RU
}

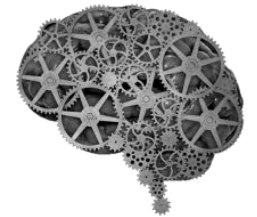

COMPANY GROUP "INTELLEKT"

\author{
Бляблина Д.А. \\ ФГБОУ ВПО «ГУУ» \\ Москва, Россия
}

doi: 10.18411/lj2016-6-1-02

\section{Бухгалтерский учет расходов и затрат на примере ОАО «СО ЕЭС»}

Аннотация: Наряду с доходами организации, большую роль для оценки эффективности ее деятельности и принятия управленческих решений играют и расходы. Ведь при сравнении доходов и расходов за период мы получаем прибыль - наиболее важный показатель для любой коммерческой организации, так как именно она является ее главной целью. Поэтому изначальное отражение и правильное ведение расходов имеет большое значение для получения качественного и достоверного финансового результата.

В соответствии с ПБУ 10/99 в бухгалтерском учете расходами организации признается уменьшение экономических выгод в результате выбытия активов (денежных средств, иного имущества) и (или) возникновения обязательств, приводящее к уменьшению капитала этой организации, за исключением уменьшения вкладов по решению участников (собственников имущества)[1].

Для эффективного учета расходы организации группируются и подразделяются по обычным видам деятельности и прочим.

Главными целями ОАО «СО ЕЭС» (Далее - Системный оператор) является обеспечение надежного энергоснабжения и качества электрической энергии, создание условий для функционирования рынка электроэнергии, реализация государственной политики в электроэнергетике, разработка и реализация научно-технической политики и внедрение новых прогрессивных 
видов техники и технологий, а также получение прибыли. Для их достижения организацией осуществляются в установленном законодательством Российской Федерации порядке следующие виды деятельности[2]:

- обеспечение соблюдения установленных параметров функционирования Единой энергетической системы России и качества электрической энергии;

- управление технологическими режимами работы объектов электроэнергетики;

- участие в организации деятельности по прогнозированию объема производства и потребления в сфере электроэнергетики, прогнозирование объема производства и потребления в сфере электроэнергетики, расчет и анализ ожидаемых балансов электроэнергии и мощности, участие в процессе формирования резерва производственных энергетических мощностей;

- разработку и представление в уполномоченный федеральный орган исполнительной власти совместно с организацией по управлению единой национальной (общероссийской) электрической сетью мероприятий, технологических схем и программ развития Единой энергетической системы России и участие в их реализации, анализ и согласование планов перспективного развития энергетических систем;

- согласование вывода в ремонт и из эксплуатации объектов электросетевого хозяйства и объектов по производству электрической и тепловой энергии, а также ввода их после ремонта и в эксплуатацию;

- выдачу субъектам электроэнергетики и потребителям электрической энергии с управляемой нагрузкой обязательных для исполнения 
оперативных диспетчерских команд и распоряжений, связанных с осуществлением функций системного оператора;

- анализ устойчивости энергосистемы, расчет допустимых потоков мощности по отдельным объектам электрической сети и их группам;

- разработку оптимальных суточных графиков работы электростанций и электрических сетей Единой энергетической системы России;

- регулирование частоты электрического тока, развитие и обеспечение функционирования систем автоматического регулирования частоты электрического тока и мощности, системной и противоаварийной автоматики;

- организацию и управление режимами параллельной работы российской электроэнергетической системы и электроэнергетических систем иностранных государств, в том числе куплю-продажу электрической энергии (мощности) в целях технологического обеспечения совместной работы российской электроэнергетической системы и электроэнергетических систем иностранных государств в порядке, установленном правилами оптового рынка;

- создание и поддержание в готовности к применению резервной системы диспетчерского технологического управления;

- участие в формировании и выдаче при присоединении субъектов электроэнергетики к единой национальной (общероссийской) электрической сети и территориальным распределительным сетям технологических требований, обеспечивающих их работу в составе Единой энергетической системы России;

- участие в осуществлении уполномоченными федеральными органами исполнительной власти контроля за техническим состоянием объектов электроэнергетики и энергопринимающих 
устройств потребителей электрической энергии, влияющих на надежность и безопасность функционирования Единой энергетической системы России;

- организацию отбора исполнителей услуг по обеспечению системной надежности, услуг по обеспечению вывода Единой энергетической системы России из аварийных ситуаций, оплату таких услуг, а также заключение договоров и оплату услуг по формированию технологического резерва мощностей в целях обеспечения надежности функционирования Единой энергетической системы России в порядке, установленном Правительством Российской Федерации;

- контроль за своевременной и надлежащей реализацией инвестиционных программ генерирующих компаний, сформированных по результатам торговли мощностью.

Расходы, понесенные на перечисленные виды деятельности, являются основными в Системном операторе.

В соответствии с положением по бухгалтерскому учету ПБУ 10/99 при формировании расходов по обычным видам деятельности должна быть обеспечена их группировка по следующим элементам:

- материальные затраты;

- затраты на оплату труда;

- отчисления на социальные нужды;

- амортизация;

- прочие затраты[1].

Для целей управления в бухгалтерском учете Системным оператором организуется учет расходов по статьям затрат. В соответствии с Приказом ФСТ России от 24.10.2014 N 1831-э "Об утверждении форм раскрытия информации субъектами рынков электрической энергии и мощности, являющимися 


\section{субъектами естественных монополий" Системный оператор раскрывает}

информацию о своей деятельности, а именно информацию о структуре и объеме

\section{затрат на оказание услуг по оперативно-диспетчерскому управлению в}

электроэнергетике по следующей форме [3]:

\begin{tabular}{|c|c|c|c|c|c|}
\hline \multirow{2}{*}{$\begin{array}{l}\text { № } \\
\Pi / \Pi \\
\end{array}$} & \multirow{2}{*}{ Показатели } & \multirow{2}{*}{ Ед. изм. } & \multicolumn{2}{|c|}{ Год } & \multirow{2}{*}{ Примечание } \\
\hline & & & план & факт & \\
\hline I & $\begin{array}{l}\text { Расходы, связанные с производством } \\
\text { и реализацией, всего, в том числе: }\end{array}$ & тыс. руб. & & & \\
\hline 1 & Материальные расходы, всего & тыс. руб. & & & \\
\hline 1.1 & в том числе на ремонт & тыс. руб. & & & \\
\hline 2 & $\begin{array}{l}\text { Расходы на оплату труда и } \\
\text { отчисления на социальные нужды }\end{array}$ & тыс. руб. & & & \\
\hline 2.1 & в том числе на ремонт & тыс. руб. & & & \\
\hline 3 & Амортизация & тыс. руб. & & & \\
\hline 4 & Прочие расходы, всего, в том числе: & тыс. руб. & & & \\
\hline 4.1 & расходы на ремонт & тыс. руб. & & & \\
\hline 4.2 & услуги сторонних организаций & тыс. руб. & & & \\
\hline 4.3 & арендная плата & тыс. руб. & & & \\
\hline 4.4 & налоги, пошлины и сборы & тыс. руб. & & & \\
\hline 4.5 & другие прочие расходы & тыс. руб. & & & \\
\hline 5 & $\begin{array}{l}\text { Расходы на организацию и оплату услуг по формированию } \\
\text { перспективного технологического резерва мощностей }\end{array}$ & тыс. руб. & & & \\
\hline 6 & $\begin{array}{l}\text { Расходы на организацию и оплату услуг по обеспечению } \\
\text { системной надежности, всего, в том числе: }\end{array}$ & тыс. руб. & & & \\
\hline 6.1 & $\begin{array}{l}\text { расходы на оплату услуг по нормированному первичному } \\
\text { регулированию частоты } \\
\text { (конкурентный отбор) }\end{array}$ & тыс. руб. & $\mathrm{x}$ & & \\
\hline 6.2 & $\begin{array}{l}\text { расходы на оплату услуг по автоматическому вторичному } \\
\text { регулированию частоты и перетоков активной мощности } \\
\text { (конкурентный отбор) }\end{array}$ & тыс. руб. & $\mathrm{x}$ & & \\
\hline 6.3 & $\begin{array}{l}\text { расходы на оплату услуг по регулированию реактивной } \\
\text { мощности } \\
\text { без производства электрической энергии (запрос } \\
\text { предложений о готовности оказывать услуги или путем } \\
\text { заключения договора с единственным возможным } \\
\text { исполнителем услуг) }\end{array}$ & тыс. руб. & $\mathrm{x}$ & & \\
\hline 6.4 & $\begin{array}{l}\text { расходы на оплату услуг по развитию систем } \\
\text { противоаварийного управления (запрос предложений о } \\
\text { готовности оказывать услуги или путем заключения } \\
\text { договора с единственным возможным исполнителем услуг) }\end{array}$ & тыс. руб. & $\mathrm{x}$ & & \\
\hline 7 & $\begin{array}{l}\text { Расходы на организацию и оплату услуг по обеспечению } \\
\text { вывода ЕЭС из аварийных ситуаций }\end{array}$ & тыс. руб. & & & \\
\hline II & Внереализационные расходы, всего & тыс. руб. & & & \\
\hline III & ИТОГО расходов (пункт I + пункт II) & тыс. руб. & & & \\
\hline IV & Налогооблагаемая прибыль & тыс. руб. & & & \\
\hline 1 & Налог на прибыль & тыс. руб. & & & \\
\hline 2 & $\begin{array}{l}\text { Нераспределенная прибыль, всего, } \\
\text { в том числе: }\end{array}$ & тыс. руб. & & & \\
\hline 2.1 & Расходы из прибыли до распределения, всего, в том числе: & тыс. руб. & & & \\
\hline 2.1 .1 & Выпадающие/излишние доходы/(расходы) прошлых лет & тыс. руб. & & & \\
\hline 2.2 & Чистая прибыль, всего, в том числе: & тыс. руб. & & & \\
\hline 2.2 .1 & Возврат заемных средств на цели инвестпрограммы & тыс. руб. & & & \\
\hline 2.2 .2 & Дивиденды по акциям & тыс. руб. & & & \\
\hline 2.2 .3 & Капитальные вложения & тыс. руб. & & & \\
\hline 2.2 .4 & Прочие расходы из прибыли & тыс. руб. & & & \\
\hline $\mathrm{V}$ & $\begin{array}{l}\text { Необходимая валовая выручка } \\
\text { (пункт III + пункт IV) }\end{array}$ & тыс. руб. & & & \\
\hline VI & $\begin{array}{l}\text { Справочно: расходы на ремонт, всего } \\
\text { (пункт } 1.1+\text { пункт } 2.1+\text { пункт } 4.1 \text { ) }\end{array}$ & тыс. руб. & & & \\
\hline
\end{tabular}


Расходы по основному виду деятельности подразделяют также на прямые и косвенные. В Системном операторе согласно Положению общества к прямым расходам относятся затраты, непосредственно связанные с оказанием услуг по оперативно-диспетчерскому управлению в части управления режимами или услуг по оперативно-диспетчерскому управлению в части обеспечения надежности:

- расходы на оплату труда персонала, участвующего в процессе оказания услуги;

- страховые взносы на обязательное пенсионное страхование, на обязательное страхование на случай временной нетрудоспособности и в связи с материнством, на обязательное медицинское страхование, на обязательное социальное страхование от несчастных случаев на производстве и профессиональных заболеваний, начисленные на суммы расходов на оплату труда;

- суммы списания расходов по приобретенным правам на использование программ для ЭВМ, баз данных, иных объектов интеллектуальных прав;

- амортизационные отчисления по нематериальным активам;

- расходы по научно-исследовательским, опытно-конструкторским и технологическим работам используемых при оказании услуг;

- услуги, работы сторонних организаций;

- величина признанного оценочного обязательства по оплачиваемым отпускам работникам, расходы на оплату труда которых являются прямыми.

Косвенные расходы - затраты, относящиеся к деятельности Системного оператора в целом, которые невозможно прямо включить в себестоимость услуг по оперативно-диспетчерскому управлению в части управления режимами, услуг по оперативно-диспетчерскому управлению в части обеспечения 
надежности или иных обычных видов деятельности, за исключением прочих расходов.

К прочим расходам относятся те расходы, которые не связанные с обычными видами деятельности организации. И в соответствии с Положением общества расходы Системного оператора, осуществление которых связанно с предоставлением за плату во временное пользование своих активов, прав, возникающих из патентов на изобретения, промышленные образцы и других видов интеллектуальной собственности, и от участия в уставных капиталах других организаций относятся к прочим расходам и отражаются на счете 91 «Прочие расходы и доходы». Расходы от списания основных средств при авариях, стихийных бедствиях и иных чрезвычайных обстоятельствах также относятся к прочим. Туда же и относятся выплаты к юбилейным датам, отраслевым наградам, конкурсам; курсовые разницы по активам и обязательствам, подлежащим к оплате в иностранной валюте; убытки прошлых лет; пени, неустойки по хозяйственным договорам; уценка имущества при переоценке; резерв по сомнительным долгам и др.[4].

В соответствии с ПБУ 10/99, Системный оператор реализует свое право признавать коммерческие и управленческие расходы в себестоимости услуг в качестве расходов по обычным видам деятельности.

Из проведенных параллелей правил и норм распределения расходов и затрат с фактическим ведением деятельности ОАО «СО ЕЭС» необходимо отметить следующее.

Достоверное формирование информации о финансовых результатах организации является очень важной задачей бухгалтерского учета и одновременно ее проблемой. Положением по бухгалтерскому учету «Расходы организаций», также как и в бухгалтерских документах OAO «СО ЕЭС» нет четкого разграничения между понятиями «расходы» и «затраты». В Положении обозначено лишь то, что организация в праве самостоятельно определять перечень статей затрат. Отсутствие четкого разграничения, определения двух 
понятий, а также инструкций по определению статей затрат является проблемой при ведении бухгалтерского учета, так как не понимая этого, бухгалтер в спорных ситуациях испытывает трудности при принятии правильного решения и отстаивании своей позиции перед проверяющими органами.

В отличие от расходов, осуществление затрат не уменьшает капитал организации, тем самым в момент их признания не оказывают влияния на прибыль.

Затраты, как сумма стоимостей использованных ресурсов, могут отражаться на Дт08,20,23,01,08 или 43 счетов в отличие от расходов, которые встречаются только на Дт90 и 91 счетах, где доходы и расходы «встречаются», формируя прибыть.

Так на протяжении длительного времени экономисты дают различные определения этим двум терминам:

А. В. Юсупова и Л. И. Хоружий считают, что затраты - это использование ресурсов. А расходы - это когда ресурсы покидают компанию[5].

О. С. Савченко и Г. И. Пашигорева пишут: «Расходы - стоимость использованных ресурсов, которые полностью израсходованы или «потрачены» в течение определенного периода для получения дохода. Этот период не обязательно совпадает с моментом действительной оплаты ресурсов. Затраты денежная оплата приобретенных товаров или услуг, которая со временем будет вычтена из прибыли (списана в расходы). Таким образом, расходы - это часть затрат, понесенных предприятием в связи с получением дохода» [6, с.94].

Я.В. Соколов считает, что затраты касаются разного использования ресурсов, в том числе относительно приобретения активов, а расходы использования лишь тех ресурсов, которые при определении прибыли хозяйствующего субъекта за данный период времени относятся к соответствующим доходам[7]. 
Таким образом, отсутствие точной трактовки и разграничения понятий приводит к образованию взглядов и определений терминов «расходы» и «затраты» с разной смысловой нагрузкой. Поэтому на данный момент организациям остается самостоятельно разграничивать эти понятия и при рассмотрении вопросов, связанных с затратами и расходами формулировать и аргументировать сущность данных понятий и их применение в том или ином контексте. Ведь без точного понимания разницы этих терминов невозможно грамотно управлять затратами и расходами предприятия.

На данный момент налоговый инспектор и аудитор больше интересуются налоговыми, а не бухгалтерскими расходами, поэтому бухгалтерская отчетность менее подвержена строгому контролю. На основании отсутствия обеспокоенности, данная проблема остается не решенной. 


\section{Литература:}

1. Положение по бухгалтерскому учету «Расходы организации» ПБУ 10/99 утвержденное приказом Минфина РФ от 6 мая 1999 г. N 33н

2. Устав Открытого акционерного общества «Системный оператор Единой энергетической системы» утвержденный распоряжением Федерального агентства по управлению государственным имуществом от «30» июня 2009 г. № 1252

3. Приказ Федеральной службы по тарифам от 24 октября 2014 г. N 1831-э "Об утверждении форм раскрытия информации субъектами рынков электрической энергии и мощности, являющимися субъектами естественных монополий"

4. Положение об учетной политике ОАО «СО ЕЭС», утвержденное приказом от 18.12.2014г. № 375

5. Юсупова А. В., Хоружий Л. И. Различия понятий «издержки», «затраты», «расходы», их отражение в российских и международных стандартах бухгалтерского учета.// Время бухгалтера, 2012 г. — № 11

6. Пашигорева Г. И., Савченко О. С. Системы управленческого учета и анализа./ Г. И. Пашигорева, О. С. Савченко - СПб.: Питер, 2002

7. Соколов Я. В. Бухгалтерский учет в зарубежных странах: учеб. / Я. В. Соколов, Ф. Ф. Бутынец, Л. Л. Горецкая, Д. А. Панков; отв. ред. Ф. Ф. Бутынец. — М.: ТК Велби, Изд-во Проспект, 2007. 